\title{
A CONCEPÇÃO SINCRÔNICA DE LÍNGUA E SUA LIMITAÇÃO EM RELAÇÃO AO TRATAMENTO DA NEOLOGIA
}

\author{
Virginia Sita Farias*
}

\begin{abstract}
RESUMO: O método sincrônico proposto por Saussure é uma abstração teórica que possibilita reconhecer as relações entre os elementos do sistema. No entanto, o estudo sincrônico da língua apresenta algumas limitações, entre as quais figura a apreensão e o tratamento dos neologismos, já que essas unidades léxicas constituem fatos de fala e não de língua. Este trabalho tem, portanto, dois objetivos: 1) discutir as razões que levaram Saussure a adotar o método sincrônico e apontar as vantagens dessa perspectiva para o estudo da língua e 2) abordar a questão da neologia, procurando discutir alguns problemas envolvidos no tratamento desse fenômeno, em especial no que concerne ao seu registro em dicionários de língua.
\end{abstract}

PALAVRAS-CHAVE: Sincronia - Neologismo - Dicionários de língua

RESUMEN: El método sincrónico que propone Saussure es una abstracción teórica que le permite identificar las relaciones entre los elementos del sistema. Sin embargo, el estudio sincrónico de la lengua presenta algunas limitaciones, entre las que figuran la comprensión y el tratamiento de los neologismos, dado que esas unidades léxicas no constituyen hechos de lengua, sino más bien hechos de habla. Este trabajo tiene dos objetivos. En primer lugar, discutir las razones que sostienen la opción de Saussure por el método sincrónico y señalar sus ventajas. En segundo lugar, exponer el tema de los neologismos, discutiendo algunos problemas involucrados en el tratamiento de esas unidades léxicas, en especial en lo concerniente a su registro en los diccionarios de lengua.

PALABRAS-CLAVE: Sincronía - Neologismo - Diccionarios de lengua

\section{INTRODUÇÃO'}

Propomos iniciar a nossa discussão a partir da análise do seguinte fragmento extraído de uma das obras mais importantes da literatura de língua portuguesa:

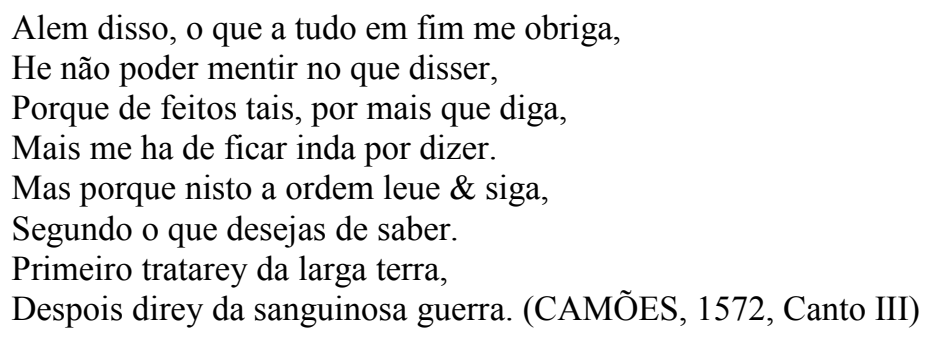

\footnotetext{
* Aluna de mestrado do PPG-Let/UFRGS. E-mail: virginiafarias@terra.com.br.

${ }^{1} \mathrm{O}$ presente artigo foi originalmente apresentado como requisito parcial de aprovação em 2007/1 à disciplina "Lingüística Geral", pertencente à área de concentração Estudos da Linguagem - Teorias do Texto e do Discurso - Lexicografia e Terminologia: Relações Textuais do PPG-Let/UFRGS.
} 
Qualquer pessoa que fosse interrogada sobre a língua em questão, possivelmente, não teria dúvida ao responder que se trata da língua portuguesa. Por outro lado, para qualquer falante nativo do português, vivendo em pleno século XXI, causaria estranheza identificar a língua do poema como a sua língua. Estamos, portanto, diante de uma situação aparentemente contraditória: a língua do poema, ao mesmo tempo, é e não é a língua portuguesa tal como a concebemos.

Além do aspecto temporal, que é o mais óbvio neste caso, há outros fatores que contribuem para que a língua do poema distancie-se da(s) língua(s) (funcionais) que falamos hoje. A leitura desse fragmento nos permite verificar que essa língua, por um lado, não corresponde à variedade (ou às variedades) do português falado no Brasil e, por outro lado, tampouco corresponde à forma como nós normalmente falaríamos. Em termos coserianos, poderíamos dizer que entre a língua do poema e a(s) línguas(s) que falamos hoje há diferenças de ordem diatópica, diastrática e diafásica, além da diferença de ordem diacrônica, mencionada anteriormente (cf. COSERIU, 2004 ${ }^{\mathrm{a}}, 2004 \mathrm{~b}, 2004 \mathrm{c}$ ). Pode-se dizer, pois, que a língua de Camões e a língua que falamos (o português do Brasil no século XXI, em suas diversas variedades) são a mesma, no sentido de que constituem a mesma língua histórica, identificada, neste caso, como a língua portuguesa. Contudo, como observa Coseriu (2004b), todas as línguas históricas apresentam variedade interna, constituindo um conjunto de línguas funcionais, diferenciadas diacrônica, diatópica, diastrática e diafasicamente. Dessa forma, a língua do poema e a língua (ou línguas, dado que todos os falantes normalmente reconhecem mais de uma língua funcional) que conhecemos hoje constituem línguas funcionais diferentes.

Neste momento, deter-nos-emos apenas no aspecto temporal, deixando de lado todos os demais fatores. É precisamente através da observação da língua no seu transcurso histórico que os fenômenos de variação e mudança ${ }^{2}$ podem ser melhor apreendidos. Muito antes da sistematização proposta por Eugenio Coseriu, a constatação de que as línguas mudam já subjazia aos estudos comparatistas, que serviram de base para a escola dos neogramáticos. O estudo comparado das línguas visava demonstrar as suas relações de parentesco e identificar as leis que atuam na regulação das transformações ${ }^{3}$.

Embora no Curso de Lingüistica Geral isso não apareça proposto tal qual expusemos anteriormente, é evidente o fato de que Saussure, como herdeiro dos estudos dos neogramáticos (cf. ROBINS, 1994, p. 219), tinha plena consciência da existência da variação e da mudança. Entretanto, e, aparentemente, de maneira contrária a essa concepção, após formalizar a distinção fundamental entre os dois tipos de lingüística, a que estuda as relações no tempo, chamada diacrônica, e a que estuda as relações no

\footnotetext{
${ }^{2}$ É importante salientar que, embora estejam relacionadas, a variação e a mudança são fenômenos distintos, já que o segundo implica, de fato, o primeiro, mas o contrário nem sempre é verdade: "By acting as a living vehicle or medium for the retraction and promotion of competing forms, which will show themselves in retrospect as members of the successive grammars of the language, it [a variação] makes change possible. This does not mean that all linguistic variation is necessarily associated with ongoing change but simply that any change which does take place assumes the presence of linguistic variation." (BYNON, 1978, p. 199) [Por atuar como um veículo ou agente vivo para a contenção e promoção de formas concorrentes, as quais se mostrarão no decurso do tempo como membros de gramáticas sucessivas da língua, a variação torna a mudança possível. Isso não significa que toda a variação lingüística está necessariamente associada a uma mudança em andamento, mas simplesmente que qualquer mudança estabelecida supõe a presença da variação lingüística].

${ }^{3}$ Sobre os estudos comparatistas e o modelo neogramático, cf. Bynon (1978, p. 17-75; 173-197).
} 
sistema $^{4}$, chamada sincrônica, Saussure deu maior destaque justamente ao estudo sincrônico.

Essa decisão metodológica adotada por Saussure é fundamental, já que são os princípios da lingüística estática que abrem espaço para as duas contribuições mais importantes do mestre genebrino. Em primeiro lugar, é somente a partir da análise de um determinado estado de língua, definido como "um espaço de tempo, mais ou menos longo, durante o qual a soma de modificações ocorridas é mínima" (SAUSSURE, 2006 [1916], p. 117-118), que se pode chegar a reconhecer as relações entre os elementos do sistema. O valor resulta dessas relações, de modo que a teoria do valor, essência do Curso de Lingüística Geral, é tributária dessa decisão metodológica. Em segundo lugar, os princípios da análise sincrônica da língua contribuíram enormemente para a ascensão da lingüística descritiva no século $\mathrm{XX}$, em detrimento da lingüística histórica, cujos estudos haviam sido preponderantes durante o século XIX ${ }^{5}$. Contudo, o fato de que Saussure tenha concedido privilégio à sincronia não significa que ele tenha ignorado os fenômenos de variação e mudança. Na verdade, ocorre precisamente o contrário: por ter plena consciência desses fenômenos é que Saussure chega à conclusão de que somente o estudo de um dado estado de língua permitiria uma descrição das relações estabelecidas. O objetivo deste trabalho, portanto, é, em primeiro lugar, comentar as razões que levaram Saussure a adotar essa metodologia, apontando as vantagens do estudo sincrônico para o desenvolvimento da lingüística moderna, e, em segundo lugar, assinalar algumas limitações desse método de trabalho, tendo em vista a problemática do tratamento lexicográfico dos neologismos. Salientamos, desde já, que o presente artigo não pretende formular uma proposta alternativa à sincronia para a análise dos neologismos, tomando como base, por exemplo, os estudos filológicos ou sociolingüísticos ${ }^{6}$. A formulação de uma proposta série para o tratamento da neologia a partir dos pressupostos de uma das correntes teóricas mencionadas demanda um estudo mais aprofundado, devendo constituir, dessa forma, um segundo passo desta pesquisa.

\section{DISCUSSÃO DA OPÇÃo DE SAUSSURE PELO MÉTODO SINCRÔNICO}

De acordo com Saussure (2006 [1916], p. 97-98), os "gramáticos", que estudaram a língua antes do surgimento dos estudos lingüísticos, já apresentavam um programa estritamente sincrônico. O primeiro mérito de Saussure, portanto, consiste no estabelecimento de uma oposição clara entre as duas lingüísticas: a diacrônica e a sincrônica. Essa distinção entre dois pontos de vista opostos para o estudo da língua, bem como o privilégio concedido ao segundo, ficam assim justificados:

A língua é um sistema do qual todas as partes podem e devem ser consideradas em sua solidariedade sincrônica.

Como as alterações jamais são feitas no bloco do sistema, e sim num ou noutro de seus elementos, só podem ser estudadas fora do sistema. Sem

\footnotetext{
${ }^{4}$ Sistema pode ser entendido, de acordo com a concepção saussuriana, como um conjunto de opções alternativas de uma língua, as quais estão subordinadas a determinadas regras que possibilitam selecionar uma das opções (cf. BUßMANN, 1983, s.v. Sprachsystem, e TRASK, 2006, s.v. sistema).

${ }^{5}$ Um panorama das escolas e tendências da lingüística moderna é apresentado em Lepschy (1975) e Robins (1994, p. 218-264).

${ }^{6}$ Para uma introdução aos estudos filológicos (comparatistas), cf. Crystal (1997, p. 294-297) e Trask (2006, s.v. etimologia, s.v. filologia e s.v. lingüística histórica). Para uma introdução aos estudos sociolingüísticos, cf. Bußmann (1983, s.v. Soziolinguistik) e Trask (2006, s.v. sociolingüística).
} 
dúvida, cada alteração tem sua repercussão no sistema; o fato inicial, porém, afetou um ponto apenas; não há nenhuma relação interna com as conseqüências que se podem derivar para o conjunto. Essa diferença de natureza entre termos sucessivos e termos coexistentes, entre fatos parciais e fatos referentes ao sistema, impede de fazer de uns e de outros a matéria de uma única ciência. (SAUSSURE, 2006 [1916], p. 102-103)

Para ilustrar a diferença entre a matéria correspondente a cada uma das lingüísticas que Saussure distingue, tomamos um exemplo do sistema fonológico do espanhol. Até o século XII, a língua espanhola conhecia a diferença entre o fonema $/ \mathrm{b} /$ (oclusivo bilabial sonoro) e o fonema / $\mathrm{v} /$ (fricativo labiodental sonoro) e seu alofone [ $\beta$ ] (fricativo bilabial sonoro). Desse modo, as grafias lobo e huebos correspondiam, respectivamente, às pronúncias ['lobo] e ['webos], enquanto que as grafias cauallo (ou cavallo) e hueuos (ou huevos), correspondiam, respectivamente, às pronúncias

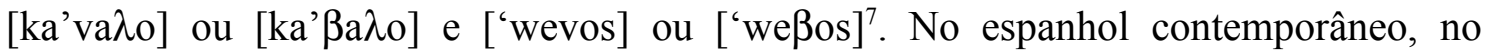
entanto, os fones [b] e [v] já não mais estabelecem uma oposição com valor fonológico, ou seja, não formam pares mínimos, como no caso de ['webos] e ['wevos]. O som [v] perdeu seu status de fonema, e passou a alofone do fonema /b/, o que afetou também o som $[\beta]$, que, conseqüentemente, passou a alofone de $/ \mathrm{b} /$. A palavra huevos hoje tem, pois, três possibilidades de pronúncia, a saber, ['webos], ['wevos] e ['weßos], as mesmas três possibilidades de pronúncia que apresentaria a palavra huebos ${ }^{8}$, que anteriormente formava um par mínimo com huevos. As relações estabelecidas entre [b], [v] e $[\beta]$ em cada distinto momento do processo evolutivo da língua espanhola são diferentes, e em conseqüência, cada um desses elementos apresenta valores diferentes em cada fase. As transformações ocorridas entre um estágio e outro, bem como as regras que operaram nessas transformações não interessam para a descrição das relações estabelecidas entre esses elementos em cada distinto estado de língua. Isso é matéria para a chamada lingüística diacrônica. A descrição das relações estabelecidas entre [b], $[v]$ e $[\beta]$ no sistema fonológico do espanhol em cada distinto estado de língua conforma a tarefa da lingüística sincrônica.

A lingüística sincrônica, preconizada por Saussure, em detrimento do estudo diacrônico, encontra sua razão de ser no fato de que é somente através da descrição do estado de língua que se pode chegar às diferentes relações pertinentes à gramática de uma língua (cf. SAUSSURE, 2006 [1916], p. 117-118), e, conseqüentemente, ao estabelecimento dos princípios fundamentais do que Saussure chama de "sistema idiossincrônico". Para que isto seja possível, é necessário descrever dois tipos de relações:

1) a relação estabelecida entre significante e significado;

2) a relação estabelecida entre um signo e os demais signos no sistema:

a) no eixo sintagmático;

b) no eixo paradigmático.

O valor lingüístico é resultado desses dois tipos de relações: a relação do significante com o significado, entre os quais é estabelecido um laço arbitrário ${ }^{9}$, e a

\footnotetext{
${ }^{7}$ Uma comparação entre os processos evolutivos fonológicos do espanhol e do português é feita em Brabo Cruz (2003).

${ }^{8}$ Em DUE (2001, s.v.), a palavra huebos aparece marcada como "antiguo".

9 Em Benveniste (1980), o laço que une significante e significado é definido como necessário, em substituição ao termo arbitrário, usado por Saussure. Jakobson (1992, p. 49) reitera a asserção de Benveniste, afirmando que: “[...] desde el punto de vista sincrónico de una comunidad lingüística que
} 
relação de um signo, resultado dessa união indissolúvel entre significado e significante, com os demais signos no sistema, considerando que um signo não existe fora dessa relação. Embora não seja esse o nosso principal foco de atenção no presente trabalho, consideramos importante comentar, ainda que brevemente, a questão do valor lingüístico, dada a sua fundamental importância.

Bouquet (1997) assinala a complexidade da teoria do valor esboçada por Saussure, na medida em que ela coordena dois fatos igualmente complexos e que, combinados, constituem a essência do fato semântico: o primeiro é a correspondência termo a termo entre a teoria do valor e a teoria do arbitrário ${ }^{10}$, e o segundo é a associação de um valor proveniente do fato sintagmático ao valor proveniente do arbitrário da língua (cf. ibid., p. 255). Esse autor reconhece, no pensamento saussuriano, seis valores distintos, que tentamos sintetizar através do esquema abaixo ${ }^{11}$ :

\begin{tabular}{|l|l|l|l|}
\hline \multirow{5}{*}{ Teoria do Valor } & \multirow{5}{*}{ Valor In absentia } & \multirow{2}{*}{ Valor interno } & Significante $\Rightarrow$ Significado \\
\cline { 3 - 4 } & & & Significado $\Rightarrow$ Significante \\
\cline { 3 - 4 } & & & Significante $\Leftrightarrow$ Significado \\
\cline { 3 - 4 } & & Valor sistêmico & \\
\cline { 3 - 4 } & & & Semântico \\
\cline { 3 - 4 } & & & \\
\hline
\end{tabular}

De acordo com Bouquet (1997, p. 239-253), a teoria do valor formulada por Saussure é o cerne do Curso de Lingüistica Geral, isto porque é a partir da teoria saussuriana do valor que se abrem caminhos para se pensar uma semântica lingüística, cujo objeto, o sentido [sic], é transversal ao conjunto de níveis de análise lingüística.

utiliza signos lingüísticos, no puede asignalárseles una naturaleza arbitraria. No es para nada arbitrario sino más bien obligatorio decir fromage por 'queso' en francés, y decir queso en español" [do ponto de vista sincrônico de uma comunidade lingüística que utiliza signos lingüísticos, não se pode outorgar a eles uma natureza arbitrária. Não é de modo algum arbitrário, mas sim obrigatório dizer fromage por 'queijo' em francês e dizer queso em espanhol].

${ }^{10}$ Bouquet (1997) reconhece dois graus do arbitrário. O primeiro grau é o do arbitrário interno do signo, que pode ser tomado a partir de três pontos de vista distintos: a) o do significante, sob o qual é arbitrário que um dado significado seja ligado a esse significante; b) o do significado, sob o qual é arbitrário que um dado significante seja ligado a esse significado, e c) o da própria relação, sob o qual é arbitrário que um dado significante e um dado significado sejam ligados ao signo. O segundo grau é o do arbitrário sistêmico do signo, que encerra, por sua vez, dois fatos arbitrários, a saber, o arbitrário do sistema fonológico e o arbitrário do sistema semântico (cf. ibid., p. 234-238).

${ }^{11}$ Essa interpretação da teoria do valor saussuriana é apresentada em Bouquet (1997, p. 254-280). 
Para Normand (1990), por sua vez, à medida que o Curso de Lingüistica Geral é uma epistemologia, é possível encontrar nele os elementos de um enfoque semântico lingüístico, ou pelo menos, a indicação de seus limites. Em síntese, da orientação sincrônica dada ao estudo da língua, resulta uma das mais (ou talvez a mais) importantes contribuições de Saussure para a lingüística, já que, na teoria do valor, encontramos o alicerce de uma disciplina semântica, ou, como prefere Bouquet (1997), o programa de uma gramática do sentido.

O estudo sincrônico foi, pois, o método escolhido por Saussure para lidar com as relações no sistema, já que determinar o valor assumido pelas "peças" no jogo somente é possível através da apreensão de um momento específico no mesmo. Esse método serviu muito bem aos propósitos de Saussure, o que, no entanto, não o impedia de enxergar a sincronia como uma abstração teórica que, embora necessária, implica, em certa medida, renunciar a precisão da análise:

Um estado absoluto se define pela ausência de transformações e como, apesar de tudo, a língua se transforma, por pouco que seja, estudar um estado de língua vem a ser, praticamente, desdenhar as transformações pouco importantes, do mesmo modo que os matemáticos desprezam as quantidades infinitesimais em certas operações, tal como no cálculo de logaritmos. (SAUSSURE, 2006 [1916], p. 118) sincronia:

Mais tarde, Jakobson (1992) também criticaria essa abstração exigida pela

En realidad, la sincronía no es para nada estática; siempre surgen cambios que también forman parte de la sincronía. La sincronía real es dinámica. La sincronía estática es una abstracción, que puede resultar útil para la investigación de la lengua con fines específicos; sin embargo, una descripción sincrónica exhaustiva de la lengua, fiel a los hechos, debe considerar constantemente la dinámica de la lengua. [...] la imagen de la lengua como un sistema uniforme y monolítico está sobresimplificada. (ibid., p. 52$)^{12}$

Além de a sincronia consistir tão somente numa abstração teórica, o método do estudo sincrônico apresenta uma segunda limitação, que é o de relegar a um segundo plano os fatos de fala (ou manifestações individuais dos falantes) ${ }^{13}$. Assim, de acordo com Saussure (2006 [1916], p. 115):

[...] tudo quanto seja diacrônico na língua, não o é senão pela fala. É na fala que se acha o germe de todas as modificações: cada uma delas é lançada, a princípio, por um certo número de indivíduos, antes de entrar em uso. [...] Mas todas as inovações da fala não têm o mesmo êxito e, enquanto permanecem individuais, não há por que levá-las em conta, pois o que estudamos é a língua; elas só entram em nosso campo de observação no momento em que a coletividade as acolhe.

\footnotetext{
${ }^{12}$ [Na verdade, a sincronia não é de forma alguma estática; sempre surgem mudanças que também fazem parte da sincronia. A sincronia real é dinâmica. A sincronia estática é uma abstração que pode ser útil para a pesquisa lingüística com fins específicos; no entanto, uma descrição sincrônica exaustiva da língua, fiel aos fatos, deve considerar constantemente a dinâmica da língua. [...] a imagem da língua como um sistema uniforme e monolítico está demasiadamente simplificada]

${ }^{13}$ Em Saussure (2006 [1916]), a fala pode ser entendida como: a) ação individual momentânea, e b) produto assistemático de uma série dessas ações (cf. COSERIU, 1967, p. 49).
} 
Assim sendo, muito mais do que a leitura do Curso de Lingüistica Geral pode nos levar a crer, língua e fala são indissociáveis (cf. COSERIU, 1967, p. 52). Esse fato corrobora a necessidade de se considerar, em certa medida, também a perspectiva diacrônica no estudo sincrônico.

O léxico é o âmbito no qual as limitações do estudo exclusivamente sincrônico são mais facilmente visíveis. Para ilustrar a discussão, analisaremos, na seção seguinte, a questão dos neologismos, em especial no que concerne ao seu tratamento nos dicionários de língua.

\title{
O TRATAMENTO (LEXICOGRÁFICO) DOS NEOLOGISMOS
}

Em Morgana (1985), apontam-se alguns fatores que explicam o fato de que, no âmbito do léxico, as limitações do método sincrônico proposto por Saussure sejam mais facilmente surpreendidas:

\begin{abstract}
Per Guilbert (1975) infatti la definizione saussuriana di sincronia [...] può valere per fonologia e morfologia, ma dà adito a molti dubbi riguardo al lessico perché 1) i suoi cambiamenti sono molto più rapidi; 2) non è un sistema chiuso (come la fonologia e la morfologia) «per la sua apertura sul referente, sull'evoluzione del mondo, del pensiero», e quindi non è teoricamente possibile definire uno stato stabile della struttura in un dato periodo; 3) poiché non è una struttura chiusa, il cambiamento non è del tutto irreversibile come, secondo i presupposti saussuriani, avviene negli altri settori della lingua. (ibid., p. 5) ${ }^{14}$
\end{abstract}

Os neologismos são o exemplo mais evidente dessa mudança extremamente rápida apontada por Morgana (1985). Essa autora define a neologia como a possibilidade de criação de unidades léxicas novas, seja com a produção de uma forma nova, seja com o surgimento de um significado novo para um significante já existente (cf. ibid., p. 1) ${ }^{15}$.

Com relação aos processos de formação de neologismos, Peruzzo (2007, p. 2637) propõe uma taxonomia que apresenta quatro grandes subdivisões: 1) processos formais, nos quais a neologia é resultado do surgimento de um novo significante a partir da transformação de um outro (composição, derivação ou redução, por exemplo): blogosfera, showmício, valerioduto, zidanada, ceva "cerveja"; 2) processos sêmicos, nos quais a neologia é resultado da atribuição de um novo significado a um significante já existente: pegador "homem que varia freqüentemente de parceira amorosa", selinho "beijo"; 3) processos de incorporação de signo, que pode dar-se pela incorporação de unidades léxicas advindas de línguas estrangeiras, pela incorporação de terminologias e mesmo pela criação de gírias: blog, call-center, spam, telemarketing; 4) processos de

\footnotetext{
${ }^{14}$ [Para Guilbert (1975), a definição saussuriana de sincronia pode valer, de fato, para a fonologia e a morfologia, mas dá cabida a muitas dúvidas com relação ao léxico, porque: 1) as suas mudanças são muito mais rápidas; 2) não é um sistema fechado (como a fonologia e a morfologia) «pela sua abertura ao referente, à evolução do mundo, do pensamento», de maneira que não é teoricamente possível definir um estado estável da estrutura em um dado período; 3) dado que não é uma estrutura fechada, a mudança não é completamente irreversível, segundo os pressupostos saussurianos, como acontece nos demais setores da língua]

${ }^{15}$ Sobre o conceito de neologia, cf. também Bußmann (1983, s.v. Neologismus), Hartmann, James (2001, s.v. neologism) e Alves (1990, p. 5-7; 2002, p. 206; 2006, p. 132).
} 
transposição funcional, fenômeno que em Alves (1990, p. 60-61) também é chamado de conversão ou derivação imprópria. Este é o caso, por exemplo, dos verbos, adjetivos e advérbios empregados substantivamente, como (o/um) não e (o/um) sim.

Os neologismos são fatos de fala, posto que constituem, ao menos num primeiro momento, uma manifestação idiossincrática. Sendo assim, a análise de uma língua através de uma perspectiva puramente sincrônica excluiria o tratamento desse tipo de unidade léxica, porque, segundo vimos, não contempla os fatos de fala, dado que, repetindo as palavras do Curso de Lingüistica Geral já citadas, "todas as inovações da fala não têm o mesmo êxito e, enquanto permanecem individuais, não há por que leválas em conta, pois o que estudamos é a língua" (SAUSSURE, 2006 [1916], p. 115). O fato de que nem todas as inovações pertinentes à fala atingem a língua é irrefutável. Assim, quando um neologismo como ligador (lançado em uma campanha publicitária de uma operadora de telefonia móvel em 2007) é criado, seu futuro é imprevisível. Um caso bastante interessante na língua portuguesa é o de imexivel, "criado" pelo exministro Antônio Rogério Magri, que, na época, sofreu várias críticas. O fato é que hoje o neologismo criado por Magri encontra-se registrado em Hou (2001, s.v.). Da mesma forma, parte das unidades léxicas que compõem o repertório de uma língua foram neologismos em algum momento. Citamos, como exemplo, abajur, achismo, futebol, gilete, sedex e time, sobre os quais não cabe dúvida de que sejam unidades léxicas pertencentes à língua portuguesa. No entanto, é necessário ressaltar que é muito difícil determinar o momento em que um dado neologismo passa do plano individual (fala) para o plano coletivo (língua).

Chegamos, pois, a um ponto crucial no âmbito dos estudos lexicográficos. A dificuldade encontrada na definição de uma metodologia para o tratamento dos neologismos reflete-se no fazer lexicográfico, sendo essa uma questão relacionada de

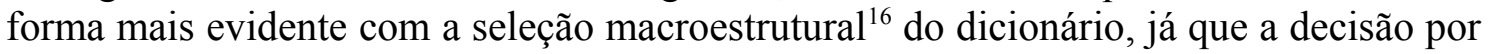
um recorte sincrônico ou por uma cobertura diacrônica do léxico conforma um critério de seleção que incide diretamente na densidade macroestrutural da obra. Contudo, não podemos esquecer que a opção pelo registro de neologismos também afeta a microestrutura ${ }^{17}$. Isso se deve ao fato de que o registro de unidades neológicas nos dicionários, pelo menos enquanto as mesmas ainda constituem fatos de fala, implica que se tenha de apresentar uma marca de uso para identificar esse tipo de lexia, o que, aliás, não é uma tarefa fácil ${ }^{18}$.

\footnotetext{
16 São concernentes ao âmbito macroestrutural todas as questões relacionadas com a seleção e a ordenação do material léxico. Sobre a macroestrutura do dicionário de língua, cf. Haensch et al. (1982, p. 452-457), Hausmann, Wiegand (1989, p. 333-337), Hartmann, James (2001, s.v. macrostructure), Landau (2001, p. 99 e ss.), Welker (2004, p. 80-107) e Bugueño (2001; 2005; 2007).

${ }^{17}$ São concernentes ao âmbito microestrutural todas as questões relacionadas com a seleção e organização das informações apresentadas nos verbetes. Sobre a microestrutura no dicionário de língua, cf. Dubois, Dubois (1971, p. 39-46), Merzagora (1987, p. 107-124), Wiegand (1989), Hausmann, Wiegand (1989, p. 340-357), Hartmann, James (2001, s.v. microstructure), Welker (2004, p. 107-177), Garriga (2003, p. 105-126) e Bugueño (2004).

18 As marcas de uso apresentadas nos dicionários que associam uma dada unidade léxica a um determinado período da história de uma língua são consideradas informações diacrônicas. As marcas diacrônicas são apresentadas em uma escala cronológica, que começa com marcações como "arcaico" e "obsoleto", chegando à indicação de unidade léxica contemporânea (são as unidades e acepções não marcadas) e, finalmente, aos "neologismos" (cf. HARTMANN; JAMES, 2001, s.v. diachronic information). Sobre a problemática das marcas de uso nos dicionários de língua, cf., também, Strehler (2001).
} 
O primeiro problema com o qual o lexicógrafo se depara é decidir o momento de registrar um neologismo, já que muitas palavras, acepções ou mesmo expressões idiomáticas surgem, são usadas durante um curto espaço de tempo, e logo desaparecem $^{19}$, enquanto outras acabam incorporando-se de um modo mais definitivo à língua, a exemplo do que ocorreu com algumas das unidades léxicas mencionadas acima. Conforme Rabanales (1984, p. 51), um dicionário deve ir sempre a posteriori, registrando o fato léxico, e não a priori, criando-o. Assim, a inclusão de unidades léxicas que possuem um número ínfimo de ocorrências em um corpus, como peitamento e sivamista ${ }^{20}$, em DUPB (2002), constitui um equívoco, agravado pelo fato de que esse dicionário pretende ser um espelho da língua portuguesa efetivamente usada no Brasil ${ }^{21}$. Convém salientar, no entanto, que em dicionários caracterizados por apresentarem uma abertura diacrônica, como Au (1999) e Hou (2001), encontramos espaço para o registro de unidades léxicas de baixa freqüência ${ }^{22}$, inclusive de casos de hapax legomena, desde que os mesmos, evidentemente, estejam devidamente marcados como tal, e, de preferência, acompanhados por datação e abonações ${ }^{23}$. Por outro lado, em obras com um viés marcadamente sincrônico, como é o caso dos dicionários de uso $^{24}$, a exemplo de DUPB (2002), bem como dos dicionários escolares ${ }^{25}$, o problema com o registro de unidades neológicas é um pouco mais grave, devido à dificuldade de se determinar quando um neologismo deixa de ser um fato de fala, tornando-se um fato de língua.

O segundo problema é a constante revisão a que devem ser submetidas as obras que registram as lexias neológicas, dado que as criações que passam do plano da fala ao plano da língua, depois de um certo tempo, deixam de ser sentidas como neologismos

\footnotetext{
${ }^{19}$ É o caso, por exemplo, das expressões ser uma brasa "ser [algo/alguém] muito bom" e ser uma uva "ser [algo/alguém] muito bonito", que surgiram em uma determinada época e foram usadas durante um breve período no Brasil, mas hoje já estão desusadas.

${ }^{20}$ Além das abonações oferecidas pelo próprio DUPB (2002, s.v. peitamento e s.v. sivamista), não foi possível recuperar nenhum outro documento que atestasse a ocorrência dessas unidades léxicas por meio de pesquisas feitas em bancos de dados abertos da internet por meio da ferramenta de busca Google. Aproveitamos para esclarecer que, embora a $W e b$ tenha sido preterida pelos lingüistas brasileiros que desenvolvem estudos em corpus durante muito tempo por ser considerada um "corpus sujo", o uso desse recurso vem ganhando espaço nos últimos anos. Kilgarriff, Grefenstette (2008), bem como Sardinha (2003), apontam algumas restrições que a Web enquanto banco de dados pode apresentar, mas não invalidam o uso da internet, especialmente como corpus de língua escrita. Além disso, considerando que os bancos de dados disponíveis para o português do Brasil ainda são parciais (cf. TAGNIN, 2005, p. 2223), o uso da Web como corpus constitui a forma mais viável de efetuarmos as nossas consultas.

${ }^{21}$ Outra prova da falta de coerência de DUPB (2002) com relação à sua proposta é o registro, s.v. bilhete, da acepção "documento; cédula: preencher um certificado para requerer um bilhete de identidade $(O M U) ;$ atual lei de emissão de passaportes exige que o requerente seja portador do bilhete de identidade (OMU)" (ibid., s.v., ac. 6). A referida acepção não é usada no português do Brasil, mas corresponde a uma acepção da palavra bilhete usada em Portugal, de modo que não se justifica sua inclusão num dicionário de usos do português brasileiro.

${ }^{22} \mathrm{O}$ traço da baixa freqüência caracteriza criações neológicas que não ultrapassaram o limite do individual. Elas são, em geral, encontradas em obras literárias, tais como os célebres neologismos de Guimarães Rosa.

${ }^{23}$ Os hapax legomena, ou unidades léxicas que apresentam apenas uma ocorrência em um corpus (cf. HARTMANN; JAMES, 2001, s.v. hapax legomenon), também podem ser considerados neologismos. Esse é, aliás, um caso típico de uso individual (portanto, fato de fala, e não de língua) que pode chegar ao conhecimento dos lexicógrafos, caso encontre-se documentado.

${ }^{24}$ Para uma análise de alguns dicionários de língua portuguesa e de língua espanhola considerados como "de uso", cf. Zanatta (2006).

${ }^{25}$ Sobre a seleção da nomenclatura e, nesse âmbito, o problema do registro de neologismos em dicionários escolares de língua portuguesa, cf. Farias (2007) e Bugueño, Farias (2008).
} 
pela comunidade lingüística, e, conseqüentemente, a atribuição de marcas de uso desse tipo já não faz mais sentido. Além disso, devemos considerar ainda, com relação mais especificamente aos estrangeirismos, a questão da dificuldade de lematização. Após sua entrada numa língua, essas formas passam por um período de flutuação até adaptaremse aos padrões fonológicos e ortográficos da língua que as recebe. As formas concorrentes rebootar, rebotar e rebutar exemplificam esse processo de acomodação aos padrões ortográficos da língua receptora. Hou (2001) registra apenas a forma rebutar, acrescentando a seguinte observação no espaço reservado ao pós-comentário semântico: "verbo malformado e inútil, por a língua já contar com os vernáculos religar, repor em funcionamento, reiniciar etc." (ibid., s.v. rebutar). Ressaltamos, no entanto, que através de pesquisas efetuadas em bancos de dados abertos da internet por meio da ferramenta de busca Google, constatamos que a forma mais usada ainda é a mais próxima da língua de origem (o inglês to reboot): encontramos 10.500 ocorrências da forma rebootar, frente a aproximadamente 75 ocorrências de rebotar e a 45 ocorrências de rebutar, a forma legitimada por Hou $(2001)^{26}$.

Para concluir nossas reflexões, assinalamos que os dicionários, em geral, apresentam uma dificuldade muito grande para lidar com os neologismos, justamente porque se trata de usos que carecem de informação sobre a sua real consagração na comunidade idiomática. Diante dessa dificuldade, propomos uma solução paliativa que, temos consciência absoluta, não resolve definitivamente o problema, mas ajuda a amenizar as conseqüências negativas que uma total carência de métodos pode ocasionar em uma obra lexicográfica. Assim sendo, assinalamos a necessidade de estabelecer uma correspondência entre a opção pelo registro de neologismos no dicionário e a definição taxonômica da obra ${ }^{27}$. Para tanto, tomamos um dos traços passíveis de caracterizar uma obra lexicográfica, de forma a opor as obras de caráter eminentemente sincrônico às de caráter diacrônico. As obras do primeiro tipo, tais como os dicionários de uso e os dicionários escolares, deveriam evitar o registro de unidades neológicas, esperando, pelo menos, até o momento em que se possa comprovar, pelo número de ocorrências, a passagem da unidade léxica a fato de língua. As obras do segundo tipo, por sua vez, podem abrir espaço para o registro de neologismos, sempre e quando sejam fornecidas informações exaustivas sobre o tipo de unidade que está sendo incluída na nomenclatura. Salientamos, no entanto, que estamos cientes de que essa é uma simplificação extrema para a caracterização das obras lexicográficas. Se fôssemos fazer um estudo exaustivo da questão, o ideal seria tomar a concepção diassistêmica da linguagem proposta por Coseriu $(1967 ; 2004$ c), dado que esta nos permitiria definir com maior exatidão as obras lexicográficas (no que concerne ao âmbito da seleção macroestrutural, obviamente), já que faríamos corresponder, primeiramente, a cada nível de estruturação da língua (sistema, norma e falar), tipos determinados de obras: os dicionários que recolhem o léxico geral situam-se no nível do sistema, os dicionários que recolhem léxicos parciais (dialetos ou linguagens especializadas, por exemplo) situam-se no nível da norma, e os dicionários que recolhem o léxico de um único autor ou de uma única obra, no nível do falar. Somente a partir do estabelecimento dessa correspondência, é que poderíamos aplicar a oposição sincronia/diacronia.

\footnotetext{
${ }^{26}$ Pesquisa realizada em 30 ago. 2007.

27 Uma definição taxonômica é uma caracterização de tipos de obras lexicográficas, através do estabelecimento de uma correspondência entre determinadas características e um genótipo específico. Algumas propostas de taxonomias são apresentadas em Haensch et al. (1982, p. 126-186), Martínez de Souza (1995), Hartmann, James (2001, s.v. typology), Landau (2001, p. 6-42), Biderman (2001), Swanepoel (2003), Welker (2004, p. 43-54) e Engelberg, Lemnitzer (2004, p. 18-22).
} 
Por fim, ressaltamos que, pelas razões aqui expostas, não é possível, pelo menos neste momento, apresentar uma solução definitiva para a questão do tratamento da neologia nos dicionários de língua. No entanto, a formulação de uma proposta, mesmo que seja deficitária em alguns aspectos, é sempre melhor do que a total ausência de critérios, situação que acaba acarretando como conseqüência a elaboração de obras lexicográficas repletas de problemas metodológicos.

\section{REFERÊNCIAS}

ALVES, Ieda Maria. Neologismo: criação lexical. São Paulo: Ática, 1990.

. Os conceitos de neologia e neologismo segundo as obras lexicográficas, gramaticais e filológicas da língua portuguesa. In: NUNES, José Horta (Org.). História do saber lexical e constituição de um léxico brasileiro. São Paulo: Humanitas/FFLCH/USP, 2002. p. 203-221.

A observação sistemática da neologia lexical: subsídios para o estudo do léxico. Alfa, São Paulo, v. 50, p. 131-144, 2006.

Au. FERREIRA, Aurélio Buarque de Holanda. Novo Aurélio Século XXI. Rio de Janeiro: Nova Fronteira, 1999. (1 CD-ROM)

BENVENISTE, Émile. Problèmes de linguistique générale. Paris: Gallimard, 1980.

BIDERMAN, Maria Tereza Camargo. Os dicionários na contemporaneidade: arquitetura, métodos e técnicas. In: OLIVEIRA, Ana Maria Pinto Pires; ISQUERDO, Aparecida Negri (Org.). As ciências do léxico: Lexicologia, Lexicografia e Terminologia I. Campo Grande: UFMS, 2001. p. 131-144.

BOUQUET, Simon. Introdução à leitura de Saussure. Tradução Carlos Salum e Ana Lúcia Franco. São Paulo: Cultrix, 1997.

BRABO CRUZ, Maria de Lourdes Otero. Breve panorama do processo evolutivo do Espanhol e do Português no plano fonológico e intercâmbios lingüístico-culturais entre essas comunidades lingüísticas. Anuario brasileño de estudios hispánicos, São Paulo, n. 13, p. 143-158, 2003.

BUGUEÑO, Félix. Problemas macroestruturais em dicionários de falsos amigos. Expressão, Santa Maria, v. 5, n. 1, p. 89-93, 2001.

Notícia sobre o comentário de forma e o comentário semântico em um dicionário de falsos amigos espanhol-português. Expressão, Santa Maria, v. 8, n. 1, p. 89-93, 2004.

O que o professor deve saber sobre a nominata do dicionário de língua. Revista Língua \& Literatura, Frederico Westphalen, v. 6/7, n. 10/11, p. 17-31, 2005.

. O que é macroestrutura no dicionário de língua? In: ISQUERDO, Aparecida Negri; ALVES, Ieda Maria (Org.). As ciências do léxico: Lexicologia, Lexicografia e Terminologia III. Campo Grande: Humanitas, 2007. p. 261-272.

BUGUEÑO, Félix; FARIAS, Virginia Sita. Desenho da macroestrutura de um dicionário escolar de língua portuguesa. In: XATARA, Cláudia; BEVILACQUA, Cleci; HUMBLÉ, Philippe (Org.). Lexicografia Pedagógica: Pesquisas e perspectivas. Florianópolis: UFSC/NUT, 2008. p. 129-167. Disponível em: http://www.cilp.ufsc.br/LEXICOPED.pdf. Acesso em: 03 set. 2008.

BUßMANN, Hadumod. Lexikon der Sprachwissenschaft. Stuttgart: Alfred Kröner, 1983.

BYNON, Theodora. Historical Linguistics. Cambridge: CUP, 1978. 
CAMÕES, Luís de. Os Lusíadas. Lisboa: em casa de Antonio Gõçaluez, 1572. Disponível em: http://purl.pt/1. Acesso em: 05 ago. 2007.

COSERIU, Eugenio. Sistema, norma y habla. In: Teoría del lenguaje y lingüistica general. $2^{\mathrm{a}}$ ed. Madrid: Gredos, 1967.

Criatividade e técnica lingüística. Os três níveis da linguagem. In:

Lições de Lingüistica Geral. Tradução Evanildo Bechara. Rio de Janeiro: Ao Livro Técnico, 2004a. p. 91-100.

A língua funcional. In: Lições de Lingüistica Geral. Tradução

Evanildo Bechara. Rio de Janeiro: Ao Livro Técnico, 2004b. p. 101-117.

Sistema, norma e falar concreto. In:_. Lições de Lingüística Geral.

Tradução Evanildo Bechara. Rio de Janeiro: Ao Livro Técnico, 2004c. p. 119-125.

CRYSTAL, David. The Cambridge Encyclopedia of Language. $2^{\mathrm{a}}$ ed. Cambridge: CUP, 1997.

DUBOIS, Jean; DUBOIS, Claude. Introduction à la lexicographie: le dictionnaire. Paris: Larousse, 1971.

DUE. MOLINER, María. Diccionario de uso del español. Madrid: Gredos, 2001. (1 CD-ROM)

DUPB. BORBA, Francisco. Dicionário de usos do português do Brasil. São Paulo: Ática, 2002.

ENGELBERG, Stefan; LEMNITZER, Lothar. Lexikographie und Wörterbuchbenutzung. 2a ed. Tübingen: Stauffenburg, 2004.

FARIAS, Virginia Sita. Dicionários escolares de língua portuguesa: uma breve análise de aspectos macroestruturais. Lusorama, Frankfurt am Main, v. 71/72, p. 160-206, 2007.

GARRIGA, Cecilio. La microestructura del diccionario: las informaciones lexicográficas. In: MEDINA, Antonia María (Coord.). Lexicografía española. Barcelona: Ariel, 2003. p. 103-126.

HAENSCH, Günther et al. La lexicografía: de la lingüística teórica a la lexicografía práctica. Madrid: Gredos, 1982.

HARTMANN, Reinhard Rudolf Karl; JAMES, Gregory. Dictionary of lexicography. London: Routledge, 2001.

HAUSMANN, Franz Joseph; WIEGAND, Herbert Ernst. Component Parts and Structures of General Monolingual Dictionaries: A Survey. In: HAUSMANN, Franz Joseph; REICHMANN, Oskar; WIEGAND, Herbert Ernst; ZGUSTA, Ladislav (Hrsgn.). Wörterbücher, dictionaries, dictionnaires. Ein internationales Handbuch zur Lexikographie. Berlin/New York: Walter de Gruyter, 1989. p. 328-360

Hou. HOUAISS, Antônio. Dicionário Houaiss da língua portuguesa. Rio de Janeiro: Objetiva, 2001. (1 CD-ROM)

JAKOBSON, Roman. El signo y el sistema de la lengua: una reafirmación de la doctrina de Saussure. In: Arte verbal, signo verbal, tiempo verbal. Tradução Mónica Mansour. México, D.F.: Fondo de Cultura Económica, 1992.

KILGARRIFF, Adam; GREFENSTETTE, Gregory. Introduction to the Special Issue on the Web as Corpus. In: FONTENELLE, Thierry (Ed.). Practical Lexicography: a reader. Oxford: OUP, 2008. p. 89-101

LANDAU, Sidney. Dictionaries: The art and craft of lexicography. Cambridge: CUP, 2001.

LEPSCHY, Giulio. A lingüistica estrutural. Tradução Nites Therezinha Feres. São Paulo: Perspectiva, 1975. 
MARTÍNEZ DE SOUZA, José. Diccionario de lexicografía práctica. Barcelona: Bibliograf, 1995.

MERZAGORA, Giovanna Massariello. La lessicografia. Bologna: Zanichelli, 1987.

MORGANA, Silvia Scotti. Le parole nuove. Bologna: Zanichelli, 1985.

NORMAND, Claudine. Le CLG: une théorie de la signification? In: $L a$ quadrature du sens. Paris: PUF, 1990.

PERUZZO, Marinella Stefani. Como lidar com os neologismos no texto jornalístico. 2007. 138f. Dissertação (Mestrado em Letras) - Instituto de Letras, UFRGS, Porto Alegre, RS.

RABANALES, Ambrosio. Qué es hablar correctamente? Revista de Educación, Santiago de Chile, v. 119, p. 49-58, 1984.

ROBINS, Robert Henry. A short history of linguistics. London/New York: Longman, 1994.

SARDINHA, Antonio Berber. Que tipo de corpus é a Web? Revista da ANPOLL, Belo Horizonte, n.15, p.191-220, 2003. Disponível em: http://www2.lael.pucsp.br/ tony/temp/publications/2003_Que_tipo_corpus_web.pdf. Acesso em: 03 jul. 2008.

SAUSSURE, Ferdinand de. Curso de lingüística geral. Tradução Antônio Chelini, José Paulo Paes e Izidoro Blikstein. 27 ed. São Paulo: Cultrix, 2006.

STREHLER, René. As marcas de uso nos dicionários. In: OLIVEIRA, Ana Maria Pinto Pires; ISQUERDO, Aparecida Negri (Org.). As ciências do léxico: Lexicologia, Lexicografia e Terminologia I. Campo Grande: UFMS, 2001. p. 171-180.

SWANEPOEL, Piet. Dictionary typologies: A pragmatic approach. In: STERKENBURG, Piet van (Ed.). A practical guide to lexicography. Amsterdam: John Benjamin, 2003. p. 44-69

TAGNIN, Stella Esther. $O$ jeito que a gente diz: expressões convencionais e idiomáticas. São Paulo: Disal, 2005.

TRASK, Robert Lawrence. Dicionário de linguagem e lingüística. Tradução Rodolfo Ilari. $2^{\mathrm{a}}$ ed. São Paulo: Contexto, 2006.

WELKER, Herbert Andreas. Dicionários: Uma pequena introdução à lexicografia. Brasília: Thesaurus, 2004.

WIEGAND, Herbert Ernst. Der Begriff der Mikrostruktur: Geschichte, Probleme, Perspektiven. In: HAUSMANN, Franz Joseph; REICHMANN, Oskar; WIEGAND, Herbert Ernst; ZGUSTA, Ladislav (Hrsgn.). Wörterbücher, dictionaries, dictionnaires. Ein internationales Handbuch zur Lexikographie. Berlin/New York: Walter de Gruyter, 1989. p. 409-462.

ZANATTA, Flávia. Análise de dicionários de uso do espanhol e do português. 2006. 82f. Trabalho de Conclusão de Curso (Licenciatura em Letras) - Instituto de Letras, UFRGS, Porto Alegre, RS. Disponível em: www6.ufrgs.br/termisul/biblioteca/TCCZanatta.pdf. Acesso em: 24 set. 2007. 